\title{
Accuracy of echocardiographic estimates of pulmonary artery pressures in pulmonary hypertension: insights from the KARUM hemodynamic database
}

\author{
Ashwin Venkateshvaran ${ }^{1,6}$ (D) Natavan Seidova ${ }^{2} \cdot$ Hande Oktay Tureli $^{3} \cdot$ Barbro Kjellström $^{1,4} \cdot$ Lars H. Lund $^{1}$. \\ Erik Tossavainen $^{5} \cdot$ Per Lindquist $^{3}$
}

Received: 11 May 2021 / Accepted: 14 June 2021 / Published online: 19 June 2021

(C) The Author(s) 2021

\begin{abstract}
Accurate assessment of pulmonary artery (PA) pressures is integral to diagnosis, follow-up and therapy selection in pulmonary hypertension (PH). Despite wide utilization, the accuracy of echocardiography to estimate PA pressures has been debated. We aimed to evaluate echocardiographic accuracy to estimate right heart catheterization (RHC) based PA pressures in a large, dual-centre hemodynamic database. Consecutive PH referrals that underwent comprehensive echocardiography within $3 \mathrm{~h}$ of clinically indicated right heart catheterization were enrolled. Subjects with absent or severe, free-flowing tricuspid regurgitation (TR) were excluded. Accuracy was defined as mean bias between echocardiographic and invasive measurements on Bland-Altman analysis for the cohort and estimate difference within $\pm 10 \mathrm{mmHg}$ of invasive measurements for individual diagnosis. In 419 subjects, echocardiographic PA systolic and mean pressures demonstrated minimal bias with invasive measurements $(+2.4$ and $+1.9 \mathrm{mmHg}$ respectively) but displayed wide limits of agreement $(-20$ to +25 and -14 to $+18 \mathrm{mmHg}$ respectively) and frequently misclassified subjects. Recommendation-based right atrial pressure (RAP) demonstrated poor precision and was falsely elevated in $32 \%$ of individual cases. Applying a fixed, median RAP to echocardiographic estimates resulted in relatively lower bias between modalities when assessing PA systolic $(+1.4 \mathrm{mmHg} ; 95 \%$ limits of agreement +25 to $-22 \mathrm{mmHg}$ ) and PA mean pressures $(+1.4 \mathrm{mmHg} ; 95 \%$ limits of agreement +19 to $-16 \mathrm{mmHg})$. Echocardiography accurately represents invasive PA pressures for population studies but may be misleading for individual diagnosis owing to modest precision and frequent misclassification. Recommendation-based estimates of $\mathrm{RAP}_{\text {mean }}$ may not necessarily contribute to greater accuracy of PA pressure estimates.
\end{abstract}

Keywords Doppler echocardiography · Right heart catheterization · Tricuspid regurgitation peak velocity

Ashwin Venkateshvaran

ashwin.venkateshvaran@ki.se

1 Cardiology Unit, Department of Medicine, Karolinska Institutet, Stockholm, Sweden

2 Department of Clinical Physiology, Danderyds Hospital, Stockholm, Sweden

3 Department of Clinical Physiology, Surgical \& Perioperative Sciences, Umeå University, Umeå, Sweden

4 Clinical Physiology, Department of Clinical Sciences Lund, Lund University, Skåne University Hospital, Lund, Sweden

5 Department of Cardiology, Public Health \& Clinical Medicine, Umeå University, Umeå, Sweden

6 Department of Cardiovascular Research, Karolinska University Hospital, 17176 Stockholm, Sweden

\section{Introduction}

Accurate hemodynamic evaluation of pulmonary hypertension $(\mathrm{PH})$ is essential for early disease identification, selection for potential therapy and during follow-up. Although $\mathrm{PH}$ diagnosis is established using right heart catheterization (RHC), transthoracic echocardiography is recommended for screening patients [1] and routinely utilized to quantify pulmonary artery (PA) pressures in addition to offering prognostic insight [2].

The accuracy and precision of echocardiography to assess PA pressures has been debated. Multiple earlier studies suggest that echocardiographic estimates of PA pressures are frequently innacurate [3-6], while more recent publications suggest good diagnostic accuracy [7-9]. These paradoxical observations may be attributed to diverse methodological 
approaches to assess accuracy in the aforementioned studies [9], and compounded to some degree by varying recommendations to quantify PH using echocardiography $[1,10]$. More recently, D'Alto and colleagues demonstrated high echocardiographic accuracy to estimate both PA mean $\left(\mathrm{PAP}_{\text {mean }}\right)$ and systolic pressures $\left(\mathrm{PAP}_{\text {systolic }}\right)$ employing Bland-Altman analysis, suggesting appropriate utility in population studies [9]. However, modest precision represented by wide limits of agreement in that study advocates greater caution when employing echocardiography to estimate $\mathrm{PH}$ severity on an individual basis.

Given the practicality, low cost and low risk of echocardiography, this study was undertaken to investigate its accuracy to estimate PA pressures in a large, prospective, dual-centre database of PH referrals. Further, we wished to study the contribution of mean right atrial pressure $\left(\mathrm{RAP}_{\text {mean }}\right)$ estimates to PA pressure estimation by comparing the accuracy of the recommended approach that takes into consideration patient-specific mean right atrial mean pressure $\left(\mathrm{RAP}_{\text {mean }}\right)$ estimates [10], and a simplified model that applies a fixed, median RAP to estimate $\mathrm{PAP}_{\text {systolic }}$ and $\mathrm{PAP}_{\text {mean }}$ in all subjects.

\section{Methods}

\section{Study population}

Consecutive patients with unexplained dyspnoea referred for RHC to PH referral centres at Karolinska University Hospital (2014-2018) and Norrlands University Hospital (2010-2015) were enrolled in the Karolinska-Umeå (KARUM) hemodynamic database. All subjects were hemodynamically stable during assessment and medical therapy was suitably titrated. The study was approved by the local ethics committees (Karolinska: DNR 2008/1695-31 \& Norrland: 07-092 M, 2014-198-32 M,2017-102-32 M). All patients provided written informed consent.

\section{Echocardiographic evaluation}

All patients underwent comprehensive echocardiography within $3 \mathrm{~h}$ of catheterization at both centers employing a Vivid E9 ultrasound system (GE Ultrasound, Horten, Norway) in keeping with current recommendations [10]. Pharmacological status was unaltered between echocardiography and RHC examinations. All studies were performed by credentialed echocardiographers with $>15$ years' experience at each center (PL/AV). 2D gray-scale images were acquired at 50-80 frames/sec and Doppler tracings were recorded using a sweep speed of $100 \mathrm{~mm} / \mathrm{sec}$. Three consecutive heart cycles were acquired in sinus rhythm and 5 in the setting of atrial fibrillation (AF). $\mathrm{TRV}_{\max }$ was measured with Continuous wave Doppler, considering the most optimal signal obtained from multiple echocardiographic windows. $\mathrm{RAP}_{\text {mean }}$ was estimated by evaluating inferior vena cava (IVC) size and collapsibility with patients in a supine position, taking care to maximize IVC diameter both during relaxed respiration and with rapid inspiration. All images were subsequently exported and analyzed offline (EchoPAC PC, version 11.0.0.0 GE Ultrasound, Waukesha, Wisconsin) by experienced investigators (PL/AV) blinded to catheterization data.

Subjects with absent or poor TR signal quality, in addition to those with a flail tricuspid valve, endocarditis or a coaptation defect resulting in massive, free-flowing jet were subsequently excluded from the analysis. TR severity was assessed semi-quantitatively and graded as mild (grade 1 ), moderate (grade 2) and moderately-severe to severe (grade 3). In keeping with American Society of Echocardiography/European Association of Cardiovascular Imaging (ASE/EACVI) recommendations, $\mathrm{RAP}_{\text {mean }}$ was estimated as $3 \mathrm{mmHg}$ if the IVC diameter was $<2.1 \mathrm{~cm}$ and collapsed $>50 \%$ during rapid inspiration and $15 \mathrm{mmHg}$ if the IVC diameter was $\geq 2.1 \mathrm{~cm}$ and collapsed $<50 \%$. In scenarios where IVC size and dynamics did not fit this paradigm (IVC diameter $<2.1 \mathrm{~cm}$ with $<50 \%$ collapse and IVC diameter $\geq 2.1 \mathrm{~cm}$ with $>50 \%$ collapse), $\mathrm{RAP}_{\text {mean }}$ was estimated as $8 \mathrm{mmHg}$ [10]. In the simplified model, median RAP was uniformly applied to corresponding $\mathrm{TRV}_{\max }$ gradients to estimate $\mathrm{PAP}_{\text {systolic }} \cdot \mathrm{PAP}_{\text {mean }}$ was calculated as $0.6 \times \mathrm{PAP}_{\text {systolic }}+2$ [11] using both recommended [10] and fixed, median RAP estimates.

\section{Invasive evaluation}

RHC was performed by experienced operators blinded to echocardiography examinations at each center using a $6 \mathrm{~F}$ Swan Ganz catheter employing jugular or femoral vein access. After suitable calibration with the zero-level set at the mid-thoracic line, pressure measurements were taken from the right atrium (RA), right ventricle (RV) and PA during end-expiration. Five to ten cardiac cycles were acquired and all pressure tracings were stored and analyzed offline using a standard hemodynamic software package (WITT Series III, Witt Biomedical Corp., Melbourne, FL).

\section{Statistical analysis}

Normality was tested using the Shapiro-Wilk test and visually reaffirmed using QQ plots. Continuous variables were expressed as mean \pm SD for parametric variables or median (interquartile range) for non-parametric variables and categorical variables were expressed as numbers and percentage. Correlations between echocardiographic and corresponding invasive measurements was performed 
using the Pearson's 2-tailed test (correlation between 2 continuous variables). Receiver operating characteristics (ROC) curve was employed to illustrate diagnostic potential of each chosen variable. An invasive PA mean pressure $\left(\mathrm{PAP}_{\text {mean }}\right) \geq 25 \mathrm{mmHg}$ was chosen to represent $\mathrm{PH}$ and $\mathrm{RAP}_{\text {mean }} \geq 7 \mathrm{mmHg}$, to represent an elevated $\mathrm{RAP}_{\text {mean }}$ [12]. Sensitivity, specificity, negative predictive value (NPV) and positive predictive value (PPV) were measured. Accuracy was assessed both for individual diagnosis and at the cohort level. Accuracy for individual diagnosis was predefined as an estimate difference within $\pm 10 \mathrm{mmHg}$ of invasive measurements. Accuracy at the cohort level was defined as the mean bias between echocardiographic and invasive measurements on Bland-Altman analysis. IBM SPSS statistics version 23.0 was employed for analysis.

\section{Results}

\section{Study population}

Of 480 subjects enrolled across the two sites, $47(10 \%)$ patients with no TR and 14 (3\%) with a coaptation defect resulting in severe, free-flowing TR were excluded, yielding 419 patients [Karolinska: $n=296(70 \%)$; Umeå: $n=123$ (30\%)] for analysis. Clinical characteristics, invasive and echocardiographic data are provided in Table 1. Fifty-two percent of the subjects were female. Twenty percent $(n=86)$ presented with AF and 7\% $(n=31)$ were on pacemaker therapy. A wide range of invasive pressures were observed for $\mathrm{RAP}_{\text {mean }}(1-29 \mathrm{mmHg}), \mathrm{PAP}_{\text {mean }}(7-99 \mathrm{mmHg})$ and $\mathrm{PAP}_{\text {systolic }}(12-136 \mathrm{mmHg}$ ). One hundred and seventy-nine patients (44\%) presented with reduced RV systolic function as suggested by TAPSE $<16 \mathrm{~mm}$ [10]. Echocardiographic images of the IVC were either not available or did not permit optimal evaluation in a small fraction $(n=32 ; 7.6 \%)$. Two hundred and forty patients (57\%) presented with mild TR, 122 (29\%) with moderate TR, and 57 (14\%) with severe TR. An illustration of echocardiographic evaluation of PA pressures is provided in Fig. 1.

\section{Accuracy of TRV $\mathrm{max}_{\max }$ to identify presence of $\mathrm{pH}$}

$\mathrm{TRV}_{\max }$ demonstrated strong association with invasive PAP $_{\text {mean }}(\mathrm{r}=0.75, \mathrm{p}<0.001)$ and a cut-off of $2.8 \mathrm{~m} / \mathrm{sec}$ demonstrated good ability to identify $\mathrm{PH}$, defined as invasive $\mathrm{PAP}_{\text {mean }} \geq 25 \mathrm{mmHg}(\mathrm{AUC}=0.87$, CI 0.84-0.91, $\mathrm{p}<0.001)$. Sensitivity analysis for different echocardiographic cut-offs to is presented in Table 2 . At $2.8 \mathrm{~m} / \mathrm{sec}$, $\mathrm{TRV}_{\text {max }}$ demonstrated $89 \%$ sensitivity and $62 \%$ specificity to identify $\mathrm{PH}$, with a $38 \%$ false positive rate. Forty-five patients $(15 \%)$ with a $\mathrm{TRV}_{\max }>2.8 \mathrm{~m} / \mathrm{sec}$ demonstrated normal PA pressures on RHC. At $3.4 \mathrm{~m} / \mathrm{sec}, \mathrm{TRV}_{\max }$ demonstrated $94 \%$
Table 1 Clinical Characteristics, invasive and echocardiographic data of patient population. Data presented as mean $\pm \mathrm{SD} /$ median $(\mathrm{Q} 1$; Q3) or number $(\%)$

\begin{tabular}{|c|c|}
\hline & $\begin{array}{l}\text { Patient } \\
\text { population } \\
(\mathrm{n}=419)\end{array}$ \\
\hline \multicolumn{2}{|l|}{ Demographics } \\
\hline Age (years) & $62 \pm 15$ \\
\hline Female & $218(52)$ \\
\hline \multicolumn{2}{|l|}{ Medical history } \\
\hline Diabetes & $59(14)$ \\
\hline Hypertension & $188(44)$ \\
\hline Atrial fibrillation & $86(20)$ \\
\hline \multicolumn{2}{|l|}{ Clinical assessment } \\
\hline Heart rate (bpm) & $72 \pm 14$ \\
\hline Body surface area $\left(\mathrm{m}^{2}\right)$ & $1.9 \pm 0.9$ \\
\hline Systolic blood pressure (mmHg) & $123 \pm 23$ \\
\hline Diastolic blood pressure (mmHg) & $70 \pm 13$ \\
\hline \multicolumn{2}{|l|}{ Indication for RHC } \\
\hline PAH or CTEPH & $169(40)$ \\
\hline Heart failure & $176(42)$ \\
\hline Post-cardiac transplantation & $8(2)$ \\
\hline Constriction & $26(6)$ \\
\hline Arrhythmogenic right ventricular dysplasia & $25(6)$ \\
\hline Others & $15(4)$ \\
\hline \multicolumn{2}{|l|}{ RHC } \\
\hline $\mathrm{PAP}_{\text {systolic }}(\mathrm{mmHg})$ & $49(37 ; 66)$ \\
\hline $\mathrm{PAP}_{\text {diastolic }}(\mathrm{mmHg})$ & $20(14 ; 25)$ \\
\hline $\mathrm{PAP}_{\text {mean }}(\mathrm{mmHg})$ & $32(23 ; 41)$ \\
\hline $\mathrm{RAP}_{\text {mean }}(\mathrm{mmHg})$ & $7(4 ; 11)$ \\
\hline \multicolumn{2}{|l|}{ Echocardiography } \\
\hline $\mathrm{RVID}_{\text {basal }}(\mathrm{mm})$ & $42 \pm 8$ \\
\hline TAPSE (mm) & $17 \pm 5$ \\
\hline RA area $\left(\mathrm{cm}^{2}\right)$ & $22 \pm 7$ \\
\hline \multicolumn{2}{|l|}{ Doppler } \\
\hline $\mathrm{TRV}_{\max }(\mathrm{m} / \mathrm{s})$ & $3.2(2.7 ; 3.8)$ \\
\hline
\end{tabular}

$R H C$ right heart catheterization, $P A H$ pulmonary arterial hypertension, CTEPH chronic thromboembolic pulmonary hypertension, $P A P$ pulmonary artery pressure, $R A P$ right atrial pressure, $R V I D$ right ventricular internal diameter end-diastole, TAPSE tricuspid annular plane systolic excursion, $T R V_{\max }$ tricuspid regurgitation max velocity, $R A$ right area

specificity and $62 \%$ sensitivity, and false positive rate fell to $5.9 \%$. Even when balanced sensitivity and specificity was identified at a $3.0 \mathrm{~m} / \mathrm{sec}$ cut-off $(80 \%$ sensitivity, $80 \%$ specificity), a $20 \%$ false positive rate was observed. Supplementary sensitivity analysis was also performed considering $\mathrm{PAP}_{\text {mean }} \geq 20 \mathrm{mmHg}$ which revealed similar results (Online Appendix Table 1). On Bland-Altman analysis, echocardiographic TR gradient demonstrated a mean bias of $+2.5 \mathrm{mmHg}$ with invasive RV-RA gradient (95\% limits of agreement +23 to $-18 \mathrm{mmHg}$ ). 


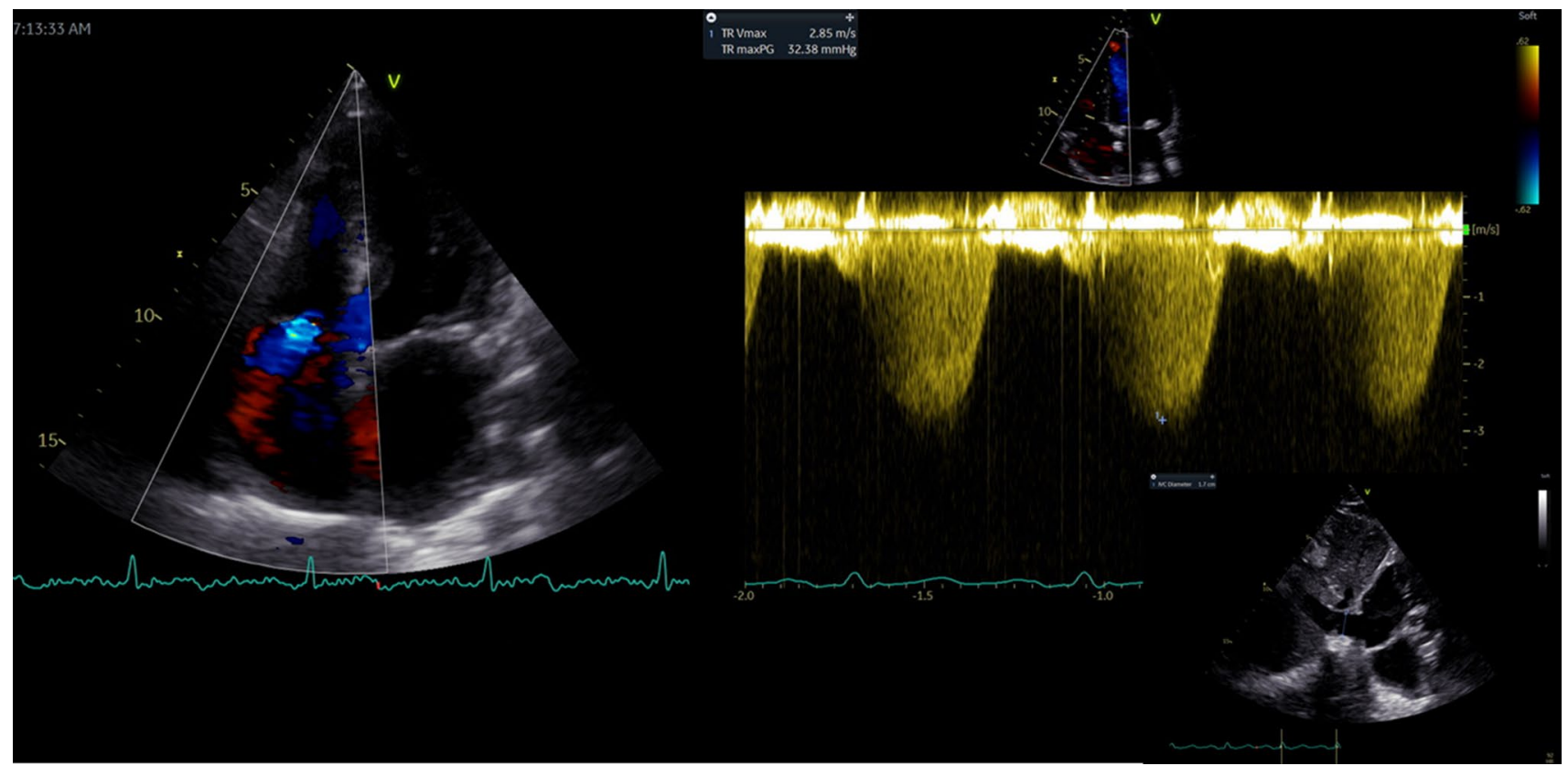

Fig. 1 Echocardiographic pulmonary artery systolic pressure $\left(\mathrm{PAP}_{\text {systolic }}\right)$ obtained by adding gradient corresponding with tricuspid regurgitation peak velocity to estimated right atrial pressure obtained from inferior vena cava size and collapse. Pulmonary artery mean pressure was calculated as $0.6 \times \mathrm{PAP}_{\text {systolic }}+2$
Table 2 Sensitivity, specificity, positive predictive value, negative predictive value for echocardiographic cut-offs to identify corresponding RHC values

\begin{tabular}{lllllll}
\hline & Cut off & RHC value & $\begin{array}{l}\text { Sensi- } \\
\text { tivity } \\
(\%)\end{array}$ & $\begin{array}{l}\text { Speci- } \\
\text { ficity } \\
(\%)\end{array}$ & $\begin{array}{l}\text { Positive pre- } \\
\text { dictive value } \\
(\%)\end{array}$ & $\begin{array}{l}\text { Negative } \\
\text { predictive value } \\
(\%)\end{array}$ \\
\hline $\mathrm{TRV}_{\text {max }}$ & $2.8 \mathrm{~m} / \mathrm{sec}$ & $\mathrm{PAP}_{\text {mean }} \geq 25 \mathrm{mmHg}$ & 89 & 62 & 85 & 68 \\
$\mathrm{TRV}_{\text {max }}$ & $3.0 \mathrm{~m} / \mathrm{sec}$ & $\mathrm{PAP}_{\text {mean }} \geq 25 \mathrm{mmHg}$ & 80 & 80 & 90 & 62 \\
$\mathrm{TRV}_{\text {max }}$ & $3.4 \mathrm{~m} / \mathrm{sec}$ & $\mathrm{PAP}_{\text {mean }} \geq 25 \mathrm{mmHg}$ & 62 & 94 & 96 & 50 \\
Estimated RAP & $7 \mathrm{mmHg}$ & $\mathrm{RAP}_{\text {mean }}>7 \mathrm{mmHg}$ & 84 & 68 & 69 & 85 \\
\hline
\end{tabular}

\section{Accuracy of IVC to estimate RAP $_{\text {mean }}$ categories}

$\mathrm{RAP}_{\text {mean }}$ estimated as per ASE/EACVI recommendations [10] demonstrated a good ability to identify invasive $\mathrm{RAP}_{\text {mean }}>7 \mathrm{mmHg}$ (AUC: 0.80; CI 0.76-0.85, $\mathrm{p}<0.001)$. However, Sensitivity analysis demonstrated a modest $68 \%$ specificity and 69\% PPV (Table 2). Further, 67 subjects $(32 \%)$ that demonstrated elevated $\mathrm{RAP}_{\text {mean }}$ estimated by echocardiography demonstrated normal invasive $\mathrm{RAP}_{\text {mean }}$. When invasive $\mathrm{RAP}_{\text {mean }}$ was plotted against echocardiographic estimates, median (IQR) for the 3, 8 and $15 \mathrm{mmHg}$ IVC-estimated subgroups were $5(3-7 \mathrm{mmHg}$ ), $8(5-10 \mathrm{mmHg})$ and $13(8-16 \mathrm{mmHg})(\mathrm{p}<0.001$ for comparison between groups). A total of 122 patients displayed an IVC-estimated RAP mean $_{\text {of }} 15 \mathrm{mmHg}$. In this subgroup, $15(12 \%)$ demonstrated an invasive $\mathrm{RAP}_{\text {mean }}<5 \mathrm{mmHg}$, and 45 (37\%), an $\mathrm{RAP}_{\text {mean }} \leq 10 \mathrm{mmHg}$. On Bland-Altman analysis, minimal bias but poor precision was observed between modalities (mean bias: $-0.1 \mathrm{mmHg}$; $95 \%$ limits of agreement +9.1 to $-9.5 \mathrm{mmHg}$ ).

\section{Accuracy of echocardiography to evaluate invasive PAP $_{\text {systolic }}$}

Echocardiographic $\mathrm{PAP}_{\text {systolic }}$ as per the ASE/EACVI approach demonstrated strong association with invasive $\operatorname{PAP}_{\text {systolic }}(\mathrm{r}=0.86, \mathrm{p}<0.001)$ (Fig. 2a). Bias and limits of agreement between echocardiographic estimates of PAP $_{\text {systolic and }}$ RHC are presented in Table 3 and Fig. 2 b. Bland-Altman analysis revealed low bias between echocardiography and RHC (mean bias $=+2.4 \mathrm{mmHg}$; CI $1.2-3.5 \mathrm{mmHg})$ with wide limits of agreement $(-20$ to $+25 \mathrm{mmHg}$ ) (Fig. 2b). Only 62\% of individual echocardiographic estimates were accurate. Echocardiography overestimated RHC by $>10 \mathrm{mmHg}$ in 92 of 387 estimates (24\%) and underestimated RHC by $>10 \mathrm{mmHg}$ in 36 of 387 
estimates (10\%). Absolute values for magnitude of overestimation were comparable with underestimation $(18 \pm 5$ vs. $18 \pm 6 \mathrm{~mm})$. When median $\mathrm{RAP}_{\text {mean }}(7 \mathrm{mmHg})$ was incorporated instead of IVC-based estimates [10], association between echocardiographic and invasive $\mathrm{PAP}_{\text {systolic }}$ remained strong $(r=0.83, p<0.001)$ (Fig. 3a). Bland-Altman analysis displayed relatively lower mean bias between methods (Bias: $+1.4 \mathrm{mmHg}, 95 \% \mathrm{CI} 0.2-2.5 \mathrm{mmHg}$ ) and comparable limits of agreement $(-22$ to $+25 \mathrm{mmHg})$ when compared with the ASE/EACVI approach (Fig. 3b).

\section{Accuracy of echocardiography to evaluate invasive PAP $_{\text {mean }}$}

Echocardiographic $\mathrm{PAP}_{\text {mean }}$ incorporating recommendationbased RAP estimates [10] demonstrated strong association with invasive $\operatorname{PAP}_{\text {mean }}(\mathrm{r}=0.81, \mathrm{p}<0.001)$ (Fig. 4a). Bias and limits of agreement between echocardiographic estimates of PAP $_{\text {mean and }}$ RHC are presented in Table 3. Bland-Altman analysis revealed low bias between methods (mean bias $=+1.9 \mathrm{mmHg} ; 95 \% \mathrm{CI} 1.0-2.6 \mathrm{mmHg}$ ) with

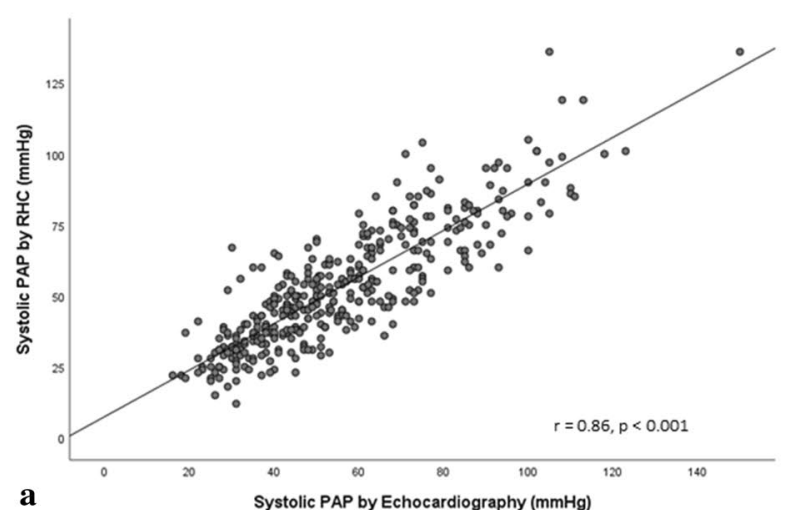

Fig. 2 a Scatter plot demonstrating correlation between PAP $_{\text {systolic }}$ estimated by echocardiography employing current ASE/EACVI recommendations and RHC. b Bland-Altman plot demonstrating agree-

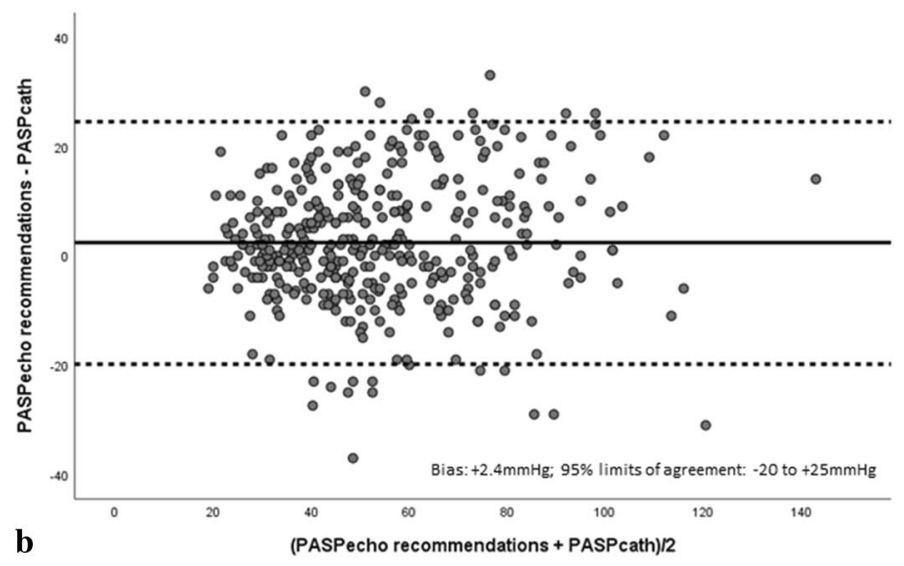

ment between $\mathrm{PAP}_{\text {systolic }}$ estimated by estimated by echocardiography employing current ASE/EACVI recommendations and RHC
Table 3 Bias and limits of agreement between echocardiographic estimates of systolic and mean pulmonary artery pressures and right heart catheterization

\begin{tabular}{lcccc}
\hline Echo estimate & Bias $\pm \mathrm{SD}$ & $95 \% \mathrm{CI}$ & $\begin{array}{l}\text { Lower limit } \\
(\text { Mean-2SD) }\end{array}$ & $\begin{array}{l}\text { Upper limit } \\
\text { (Mean + 2SD) }\end{array}$ \\
\hline $\mathrm{PAP}_{\text {systolic (ASE/EACVI) }(\mathrm{mmHg})}$ & $+2.4 \pm 11$ & $1.2-3.5$ & -20 & +25 \\
$\mathrm{PAP}_{\text {systolic (RAP }=7 \mathrm{mmHg})(\mathrm{mmHg})}$ & $+1.4 \pm 12$ & $0.2-2.5$ & -22 & +25 \\
$\mathrm{PAP}_{\text {mean (ASE/EACVI) }(\mathrm{mmHg})}$ & $+1.9 \pm 8$ & $1.0-2.6$ & -14 & +18 \\
$\mathrm{PAP}_{\text {mean (RAP = 7 mmHg) }(\mathrm{mmHg})}$ & $+1.4 \pm 9$ & $0.5-2.2$ & -16 & +19 \\
\hline
\end{tabular}

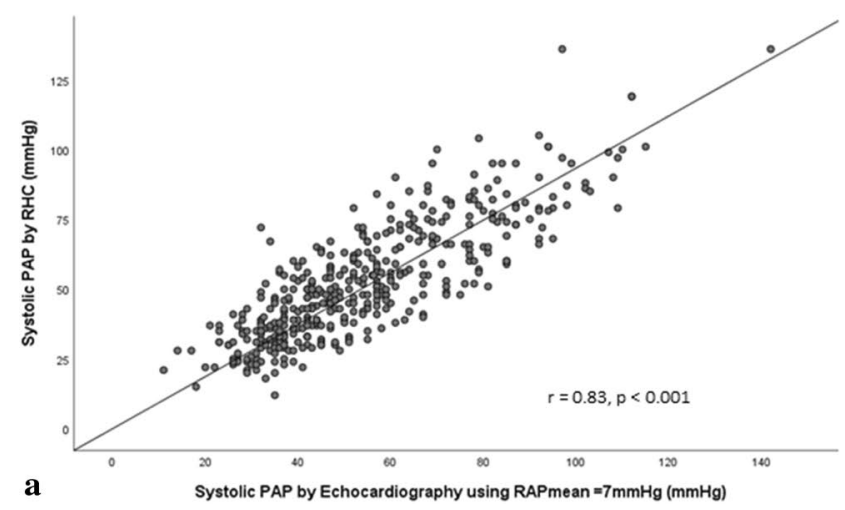

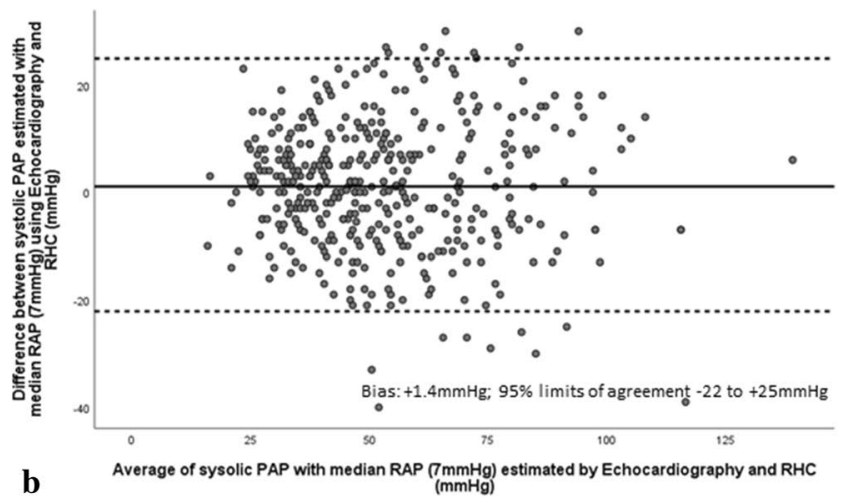

Fig. 3 a Scatter plot demonstrating correlation between $\mathrm{PAP}_{\text {systolic }}$ estimated by echocardiography using RAP $=7$ mmHg and RHC. b Bland-Altman plot demonstrating agreement between $\mathrm{PAP}_{\text {systolic }}$ estimated by estimated by echocardiography using $\mathrm{RAP}=7 \mathrm{mmHg}$ and $\mathrm{RHC}$ 


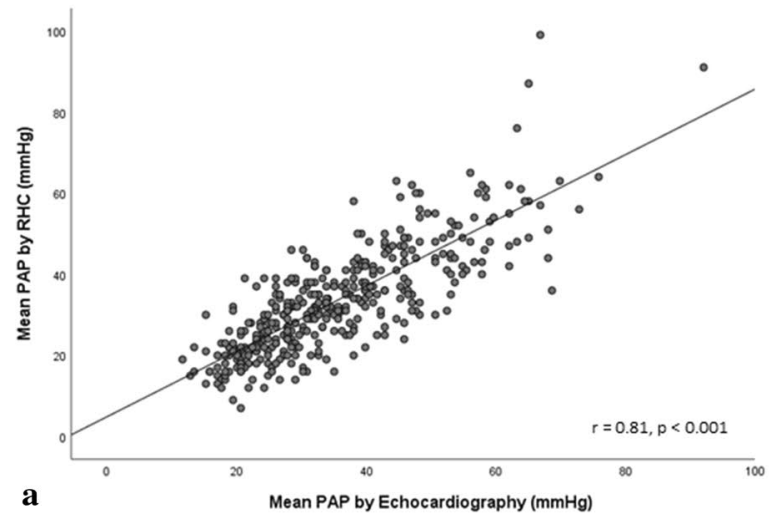

Fig. 4 a Scatter plot demonstrating correlation between $\mathrm{PAP}_{\text {mean }}$ estimated by echocardiography employing current ASE/EACVI recommendations and RHC. b Bland-Altman plot demonstrating agreement

modest precision (limits of agreement $=-14$ to $+18 \mathrm{mmHg}$ ) (Fig. 4b). Applying an $\mathrm{RAP}_{\text {mean }}=7 \mathrm{mmHg}$ to echocardiographic $\mathrm{PAP}_{\text {mean }}$ lowered bias between methods (mean bias $=+1.3 \mathrm{mmHg}$; 95\% CI $0.5-2.2 \mathrm{mmHg}$ ) and showcased comparable limits of agreement $(-16$ to $+19 \mathrm{mmHg})$ (Fig. 5b).

\section{Discussion}

In the large, dual-centre KARUM hemodynamic database, echocardiographic PA pressures were reasonably accurate, demonstrating strong association and minimal bias with corresponding pressures obtained by RHC. However, wide limits of agreement in addition to frequent misclassification suggests modest precision and precludes wider echocardiographic utilization to quantify $\mathrm{PH}$ severity in individual cases. An important observation was that recommended

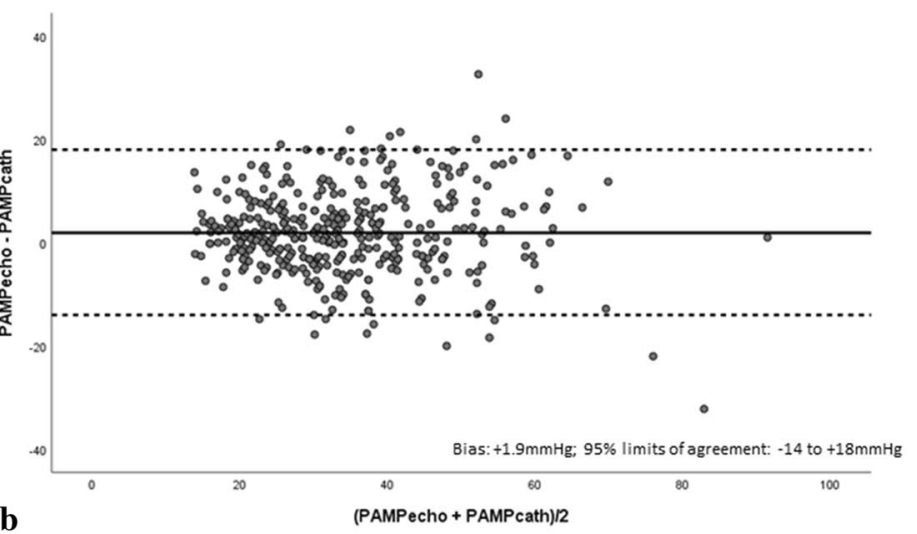

between $\mathrm{PAP}_{\text {mean }}$ estimated by echocardiography employing current ASE/EACVI recommendations and RHC

echocardiographic estimates of $\mathrm{RAP}_{\text {mean }}$ were falsely elevated in more than 1 in 3 subjects and incorporation of these estimates to calculate $\mathrm{PAP}_{\text {systolic }}$ and $\mathrm{PAP}_{\text {mean }}$ resulted in relatively higher mean bias with RHC than when the median estimate was considered for all subjects.

Interest in the utility of echocardiography to estimate PA pressures emerged with early studies suggesting a significant correlation between TR-derived estimates and invasive pulmonary pressures [13-15]. Since then, estimation of $\mathrm{TRV}_{\max }$ has been routinely utilized to grade $\mathrm{PH}$ probability $[1,16]$ and to derive PA systolic pressures using the Bernoulli equation. In keeping with earlier studies, we demonstrate that despite a significant correlation between invasive and echocardiographic measurements, frequent misclassifications may occur when individual cases are considered [3, 4]. A number of reasons have previously been proposed to explain poor accuracy in the setting of specific cases, and these have been considered and explored in our work. First,
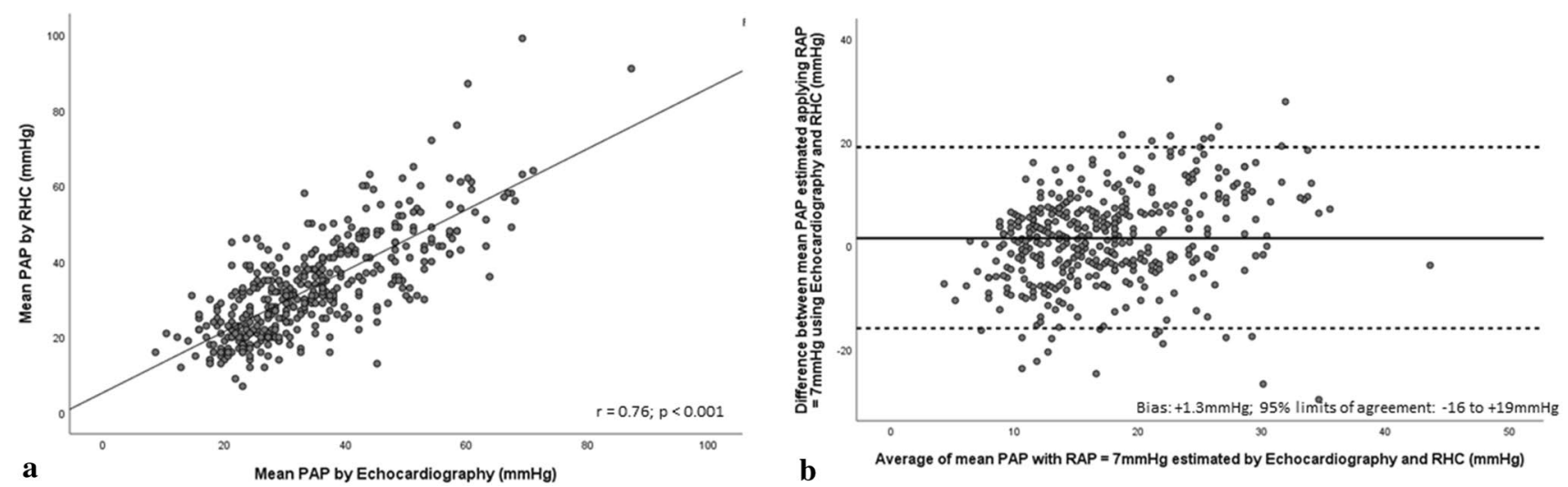

Fig. 5 a Scatter plot demonstrating correlation between $\mathrm{PAP}_{\text {mean }}$ estimated by echocardiography employing RAP $=7 \mathrm{mmHg}$ and RHC. $\mathbf{b}$ BlandAltman plot demonstrating agreement between $\mathrm{PAP}_{\text {mean }}$ estimated by echocardiography employing $\mathrm{RAP}=7 \mathrm{mmHg}$ and $\mathrm{RHC}$ 
poor agreement with invasive pressures has been previously documented in subjects with absent [17] and severe, freeflowing TR secondary to a coaptation defect [18]. Both these groups were excluded from our analysis to circumvent any bias or negative influence on our results. Second, application of the Bernoulli equation to TR velocity to calculate pressure gradient is inherently error-prone, as even small errors in absolute measurement result in exponential differences in $\mathrm{PAP}_{\text {systolic }}$ estimates. Certain international recommendations hence encourage the use of absolute velocities instead $[1,16]$. Our data shows that the recommended $2.8 \mathrm{~m} / \mathrm{sec}$ cut-off for intermediate-probability $\mathrm{PH}$ misclassified one in three subjects and raising the cut-off to $3.4 \mathrm{~m} / \mathrm{sec}$ resulted in a drop in sensitivity, thereby warranting re-evaluation of these recommended values. Finally, the integration of IVC-derived RAP estimates to corresponding TR gradients is recommended to calculate $\mathrm{PAP}_{\text {systolic }}[10]$. The reliability of this method to represent invasive $\mathrm{RAP}_{\text {mean }}$ has been debated [19-24], with certain studies suggesting modest or no association [20, 21, 24]. While IVC-estimated RAP demonstrated good ability to identify elevated invasive $\mathrm{RAP}_{\text {mean }}$ in our study, accuracy of recommended cut-offs to represent invasive pressures was poor and may explain the frequent misrepresentation of pulmonary systolic pressures. When a fixed median RAP of $7 \mathrm{mmHg}$ was considered in the population, association was still strong and bias between echocardiographic and invasive $\mathrm{PAP}_{\text {systolic }}$ and $\mathrm{PAP}_{\text {mean }}$ readings was actually lower in our study, suggesting that these recommended estimates may offer no additional advantage to PA pressure assessment [25]. A recent study suggests that echocardiography frequently underestimates PA pressures owing to the inability to accurately assess elevated RA pressures during exercise [7]. Our findings suggest that the echocardiographic assessment of $\mathrm{RAP}_{\text {mean }}$ is frequently inaccurate even during rest, and results in frequent overestimation of invasive pressures. Objective assessment of the IVC demonstrates inherent technical limitations related to excessive translation during rapid inspiration [26] and has been previously reported to be inaccurate in athletes [27] and patients on mechanical ventilation [24]. Recent studies suggest that advanced techniques such as speckle-tracking based right atrial reservoir strain [28] and 3D volumes [29] may provide a more accurate measure of $\mathrm{RAP}_{\text {mean }}$, but these findings require further validation in larger cohorts.

Our study also corroborates earlier findings that suggest modest echocardiographic precision to reflect invasive PA pressures when individual cases are concerned [3, 4, 9, 30], but an appropriate method for population studies given its high accuracy at a cohort level [9]. Echocardiography remains a practical, inexpensive and safe screening tool to arouse suspicion of $\mathrm{PH}$, offers additional etiological insight in addition to complementary information on ventricular structural and/or functional aberrations. Further, aggravations in TR severity assessed by Doppler have been associated with worsening prognosis irrespective of PA pressures and right heart failure [31]. From a clinical stand point, our study suggests that echocardiography is useful to raise suspicion of $\mathrm{PH}$ and accurately represents invasive PA pressures for population studies, but sole reliance to quantify PA pressure elevations for individual diagnosis may be frequently inaccurate. A diagnostic algorithm that combines hemodynamic information with structural indices of right-heart structure and function may vastly improve accuracy of non-invasive $\mathrm{PH}$ estimation for individual cases and needs to be explored.

The use of fluid-filled catheters instead of high-fidelity manometer-tipped catheters for pressure measurement might introduce additional error and may be considered a limitation in this study. Additionally, we did not adopt a core lab approach to evaluation of echocardiographic images in this study and inter-operator and inter-evaluator variability may be considered a limitation. However, a standard international acquisition and analysis protocol was followed by two experienced echocardiographers with over 15 years' experience. Finally, we did not employ agitated saline to boost weak TR signals in this study, but chose instead to exclude unanalyzable signal registrations from the analysis. Fewer cases may have been excluded with contrast use and this may be considered a limitation.

\section{Conclusions}

Echocardiography accurately represents invasive PA pressures and is, hence, appropriate for population studies. However, modest precision and frequent misclassification preclude its utility for evaluation of $\mathrm{PH}$ severity in individual cases. Recommendation-based estimates of $\mathrm{RAP}_{\text {mean }}$ frequently overestimate corresponding invasive measurements and do not necessarily contribute to greater accuracy of pulmonary artery (PA) pressure estimates.

Supplementary Information The online version contains supplementary material available at https://doi.org/10.1007/s10554-021-02315-y.

Author contributions AV and PL conceptualized the study, acquired and analysed data and drafted the work; NS and HT analysed data, BK, LHL and ET critically reviewed the draft and provided intellectual inputs. All authors reviewed and approved the final manuscript.

Funding Open access funding provided by Karolinska Institute. AV is supported by grants from the Swedish Association for pulmonary hypertension; LHL is supported by grants from the Swedish Research Council [grants 2013-23897-104604-23 and 523-2014-2336], Swedish Heart Lung Foundation [grants 20100419 and 20120321], Stockholm 
County Council [grants 20110120 and 20140220] and Swedish Society of Medicine [grants 174111 and 504881].

Data availability Data that support the findings of this study are available from the corresponding author (AV) upon reasonable request.

\section{Declarations}

Conflict of interests All authors have no potential conflict of interest related to this work

Ethical approval The study was approved by the local ethics committees (Karolinska: DNR 2008/1695-31 \& Norrland: 07-092 M, 2014198-32 M,2017-102-32 M).

Informed consent All patients provided written informed consent.

Open Access This article is licensed under a Creative Commons Attribution 4.0 International License, which permits use, sharing, adaptation, distribution and reproduction in any medium or format, as long as you give appropriate credit to the original author(s) and the source, provide a link to the Creative Commons licence, and indicate if changes were made. The images or other third party material in this article are included in the article's Creative Commons licence, unless indicated otherwise in a credit line to the material. If material is not included in the article's Creative Commons licence and your intended use is not permitted by statutory regulation or exceeds the permitted use, you will need to obtain permission directly from the copyright holder. To view a copy of this licence, visit http://creativecommons.org/licenses/by/4.0/.

\section{References}

1. Galiè N et al (2015) 2015 ESC/ERS guidelines for the diagnosis and treatment of pulmonary hypertension: the joint task force for the diagnosis and treatment of pulmonary hypertension of the European society of cardiology (ESC) and the European respiratory society (ERS): endorsed by: association for European paediatric and congenital cardiology (AEPC), international society for heart and lung transplantation (ISHLT). Eur Heart J 37(1):67-119

2. Bossone E et al (2013) Echocardiography in pulmonary arterial hypertension: from diagnosis to prognosis. J Am Soc Echocardiogr 26(1):1-14

3. Fisher MR et al (2009) Accuracy of Doppler echocardiography in the hemodynamic assessment of pulmonary hypertension. Am J Respir Crit Care Med 179(7):615-621

4. Rich JD, Shah SJ, Swamy RS, Kamp A, Rich S (2011) Inaccuracy of Doppler echocardiographic estimates of pulmonary artery pressures in patients with pulmonary hypertension: implications for clinical practice. Chest 139(5):988-993

5. Denton C, Cailes J, Phillips G, Wells A, Black C, Bois Rd (1997) Comparison of Doppler echocardiography and right heart catheterization to assess pulmonary hypertension in systemic sclerosis. Br J Rheumatology 36(2):239-243

6. Arcasoy SM et al (2003) Echocardiographic assessment of pulmonary hypertension in patients with advanced lung disease. Am J Respir Crit Care Med 167(5):735-740

7. Obokata $\mathrm{M}$ et al (2020) Noninvasive evaluation of pulmonary artery pressure during exercise: the importance of right atrial hypertension. Eur Respir J. https://doi.org/10.1183/13993003. 01617-2019
8. Greiner S et al (2014) Reliability of noninvasive assessment of systolic pulmonary artery pressure by Doppler echocardiography compared to right heart catheterization: analysis in a large patient population. J Am Heart Assoc 3(4):e001103

9. D'Alto M et al (2013) Accuracy and precision of echocardiography versus right heart catheterization for the assessment of pulmonary hypertension. Int J Cardiol 168(4):4058-4062

10. Lang RM et al (2015) "Recommendations for cardiac chamber quantification by echocardiography in adults: an update from the American society of echocardiography and the European association of cardiovascular imaging." Eur Heart J Cardiovasc Imaging 16(3):233-270

11. Chemla D et al (2004) New formula for predicting mean pulmonary artery pressure using systolic pulmonary artery pressure. Chest 126(4):1313-1317

12. Davidson C, Fishman R, Bonov R (1998) "Cardiac catheterization. W: Braunwald E. red," Heart disease. A textbook of cardiovascular medicine. WB Saunders Company, Philadelphia, pp 177-215

13. Yock PG, Popp RL (1984) Noninvasive estimation of right ventricular systolic pressure by Doppler ultrasound in patients with tricuspid regurgitation. Circulation 70(4):657-662

14. Currie PJ et al (1985) Continuous wave Doppler determination of right ventricular pressure: a simultaneous Doppler-catheterization study in 127 patients. J Am Coll Cardiol 6(4):750-756

15. Berger M, Haimowitz A, Van Tosh A, Berdoff RL, Goldberg E (1985) Quantitative assessment of pulmonary hypertension in patients with tricuspid regurgitation using continuous wave Doppler ultrasound. J Am Coll Cardiol 6(2):359-365

16. Augustine DX et al (2018) Echocardiographic assessment of pulmonary hypertension: a guideline protocol from the British society of echocardiography. Echo Res Pract 5(3):G11-G24

17. Mukerjee D et al (2004) Echocardiography and pulmonary function as screening tests for pulmonary arterial hypertension in systemic sclerosis. Rheumatology 43(4):461-466

18. Fei B et al (2017) Impact of severe tricuspid regurgitation on accuracy of systolic pulmonary arterial pressure measured by Doppler echocardiography: analysis in an unselected patient population. Echocardiography 34(7):1082-1088

19. Moreno FL, Hagan AD, Holmen JR, Pryor TA, Strickland RD, Castle CH (1984) Evaluation of size and dynamics of the inferior vena cava as an index of right-sided cardiac function. Am J Cardiol 53(4):579-585

20. Mintz GS, Kotler MN, Parry WR, Iskandrian A, Kane S (1981) Reat-time inferior vena caval ultrasonography: normal and abnormal findings and its use in assessing right-heart function. Circulation 64(5):1018-1025

21. Nakao S, Come PC, McKay RG, Ransil BJ (1987) Effects of positional changes on inferior vena caval size and dynamics and correlations with right-sided cardiac pressure. Am J Cardiol 59(1):125-132

22. Simonson JS, Schiller NB (1988) Sonospirometry: a new method for noninvasive estimation of mean right atrial pressure based on two-dimensional echographic measurements of the inferior vena cava during measured inspiration. J Am Coll Cardiol 11(3):557-564

23. Kircher B, Himelman R, Schiller N (1988) Right atrial pressure estimation from respiratory behavior of the inferior vena cava. Circulation 78(suppl II):550

24. Jue J, Chung W, Schiller NB (1992) Does inferior vena cava size predict right atrial pressures in patients receiving mechanical ventilation? J Am Soc Echocardiogr 5(6):613-619

25. Brennan JM et al (2007) Reappraisal of the use of inferior vena cava for estimating right atrial pressure. J Am Soc Echocardiogr 20(7):857-861 
26. Rudski LG et al (2010) Guidelines for the echocardiographic assessment of the right heart in adults: a report from the American society of echocardiography: endorsed by the European association of echocardiography, a registered branch of the European society of cardiology, and the Canadian society of echocardiography. J Am Soc Echocardiogr 23(7):685-713

27. Goldhammer E, Mesnick N, Abinader EG, Sagiv M (1999) Dilated inferior vena cava: a common echocardiographic finding in highly trained elite athletes. J Am Soc Echocardiogr 12(11):988-993

28. Miah N, Faxén UL, Lund LH, Venkateshvaran A (2020) Diagnostic utility of right atrial reservoir strain to identify elevated right atrial pressure in heart failure. Int J Cardiol. https://doi.org/10. 1016/j.ijcard.2020.09.008

29. Patel AR et al (2011) Echocardiography to evaluate right atrial pressure in acutely decompensated heart failure: correlation with invasive hemodynamics. JACC: Cardiovasc Imaging 4(9):938-945

30. Farber HW, Foreman AJ, Miller DP, McGoon MD (2011) REVEAL registry: correlation of right heart catheterization and echocardiography in patients with pulmonary arterial hypertension. Congest Heart Fail 17(2):56-63

31. Wang $\mathrm{N}$ et al (2019) Tricuspid regurgitation is associated with increased mortality independent of pulmonary pressures and right heart failure: a systematic review and meta-analysis. Eur Heart J 40(5):476-484

Publisher's Note Springer Nature remains neutral with regard to jurisdictional claims in published maps and institutional affiliations. 